Recebido: 20/12/2016

Aprovado: 01/01/2017

\title{
D. Luís da Cunha e os correios portugueses: uma leitura de passagens das Instruções políticas e do Testamento político
}

Romulo Valle Salvino*

\begin{abstract}
Resumo: D. Luís da Cunha é figura ímpar na história da diplomacia luso-brasileira. É reconhecida a importância de suas ideias e trabalho tanto para a formação territorial do Brasil quanto para a configuração geopolítica da Europa do início do século XVIII. Voltou-se para as mais prementes questões de seu tempo, diante das quais se posicionou não só por meio da ação diplomática e de um decidido apoio às ciências e às artes, mas como conselheiro de governantes. Dentre as soluções propostas por ele para o desenvolvimento do comércio e para o incremento das receitas régias, encontram-se os trechos das Instruções políticas e do Testamento político relativas ao serviço postal. Este artigo visa a apresentar e a fazer uma breve análise dessas passagens, à luz de alguns apontamentos sobre a situação histórica dos correios na época.
\end{abstract}

Palavras-chave: Correio-mor; D. Luis da Cunha; Antigo Regime.

\begin{abstract}
D. Luís da Cunha is an outstanding figure in the history of Portuguese-Brazilian diplomacy. The importance of his ideas and work is recognized both for the territorial formation of Brazil and for the geopolitical configuration of the early eighteen century Europe. He turned to the most pressing questions of his time, before which he posed himself not only through diplomatic action and a determined support for the sciences and the arts, but as a councilor of rulers. Among the solutions proposed by him for the development of commerce and the increase of royal revenues are the excerpts from the Instruções Políticas and the Testamento Politico concerning the postal service. This article aims to present and to make a brief analysis of these passages, in the light of some notes on the historical situation of the post office at the time.
\end{abstract}

Keywords: Kingdom Postmaster; D. Luis da Cunha; Old Regime.

\footnotetext{
${ }^{*}$ Mestre em Comunicação e Semiótica - PUC/SP. Doutorando do Programa de Pós-Graduação em História da Universidade de Brasília. Artigo elaborado graças à bolsa concedida pela Empresa Brasileira de Correios e Telégrafos.
} 
Um homem de seu tempo, com os olhos no futuro.

Embora haja vários estudos sobre a vida e a obra de D. Luís da Cunha, ainda existe facetas pouco exploradas nelas, importantes não só para a história da diplomacia lusobrasileira, mas também para um melhor entendimento de determinadas mudanças na cultura política de seu tempo. A sua trajetória intelectual e diplomática assume uma posição de vanguarda na época em que viveu. Seus escritos - como não poderia deixar de ser, profundamente imersos em determinado contexto histórico - discutem, às vezes, mudanças que somente conseguiriam ganhar corpo décadas depois de sua morte. Todavia, afirmar isso não é apontar uma suposta clarividência do autor, nem acreditar em um movimento teleológico, em que a história viria confirmar suas palavras. É reconhecer que determinadas ideias podem brotar como hipóteses ou propostas estratégicas, com os horizontes possíveis em seu tempo, tanto no que se refere à sua exequibilidade quanto aos próprios limites culturais de sua formulação, e deitar raízes capazes de renascerem mais à frente, reposicionadas diante de novos contextos e possibilidades históricas.

No caso deste trabalho, procurei me concentrar em uma questão que, embora possa ser considerada marginal na obra do grande diplomata, indicia, em linhas gerais, a estruturação de seu modo de pensar: a leitura de duas pequenas passagens, das Instruções políticas (1736) e do Testamento Político (1749), que versam sobre os correios lusos. Tais textos demonstram que, já na primeira metade do século XVIII, Cunha propôs, ainda que de modo incipiente, um debate em torno da possível retomada pela coroa dos direitos de exploração do monopólio postal, em mãos da família dos Mata desde o princípio da centúria anterior. Tal discussão somente teria um desfecho a partir de 1797, quando das reformas conduzidas por D. Rodrigo de Sousa Coutinho, em que a administração dos Correios foi finalmente encampada pelo governo português, mediante uma vultosa indenização aos seus antigos detentores. ${ }^{1}$

No intervalo de cerca de uma década entre os dois textos que se detêm sobre a questão, é possível perceber pequenas, mas significativas, mudanças de abordagem, ainda que o argumento principal tenha se mantido. Para discutir tal transformação, serão analisadas aqui primeiramente as Instruções, por ser o texto mais antigo, e depois o Testamento, tendo como pano de fundo, em ambos os casos, algumas informações gerais sobre o correio português na época. Como se verá, além dos indícios de que o diplomata buscara informar-se mais profundamente sobre o assunto, no caso do Testamento emerge o problema das comunicações

\footnotetext{
${ }^{1}$ Sobre as reformas postais do final do século XVIII, ver: SOBRAL NETO, 2005: 46-66.
} 
entre o reino e o Brasil, condizente com uma visão geopolítica mais ampla que se desenvolvera naqueles anos.

Uso, neste artigo, o substantivo "geopolítica" não no sentido estrito de uma ciência ou disciplina que estuda as relações entre a política e o território, mas em uma acepção mais ampla de conjunto de estratégias propostas ou utilizadas para conquistar, governar e ampliar um território ou domínio, ou para regular política e economicamente as relações ou os limites geográficos entre territórios ou domínios diferentes. Desse modo, "geopolítica" não é compreendida aqui apenas no plano internacional, mas pode referir-se a um conjunto de medidas aplicáveis a um território específico.

Embora o termo somente tenha sido criado no início do século XX por Rudolf Kjellén, o adjetivo dele derivado tem sido utilizado, em diversos campos de saber, para qualificar ações históricas anteriores. A historiografia o tem empregado para caracterizar, inclusive, o pensamento e a ação de D. Luís da Cunha. Júnia Ferreira Furtado, por exemplo, o chamou de “oráculo da geopolítica portuguesa." Abílio Diniz Silva, ao tratar das propostas de Cunha para diminuir as desvantagens portuguesas diante da Espanha, fala em "situação geopolítica de Portugal". Nesses dois casos, seja como substantivo seja como adjetivo, o termo remete principalmente à conjuntura internacional, com uma marcada preocupação com a atuação de D. Luís no traçado das fronteiras sul-americanas na abordagem de Furtado. Maria Fernanda Bicalho, todavia, ao dizer que a "[...] a cidade do Rio de Janeiro se tornou polo central e estratégico das grandes questões geopolíticas da monarquia portuguesa [...]”, aplica a palavra, ao ambiente interno do império luso, ainda que numa perspectiva ultramarina. É nesse sentido que também a emprego aqui, inclusive, no que se refere à administração interior dos domínios reinóis. $^{2}$

É importante lembrar que a palavra "território", tão importante para o conceito de "geopolítica", já era utilizada na primeira metade do século XVIII, mas estava sendo construída, ainda, a noção desse "território" como o campo de relações entre a soberania e uma população administrável e disciplinável. ${ }^{3}$ Como se procurará demonstrar até o fim deste trabalho, o enfoque de D. Luís da Cunha sobre o correio transitou, entre as Instruções e o Testamento, de uma maior ênfase aos aspectos fiscais e financeiros para uma preocupação

\footnotetext{
${ }^{2}$ SILVA, 2001: 151; FURTADO, 2010: 373-400; FURTADO, 2013: 29; BICALHO, 2011: 41. Para uma visão rápida sobre o conceito de "geopolítica", consultar: BOBBIO; MATTEUCCI; PASQUINO, 2000: 544-545.

${ }^{3}$ A respeito das acepções da palavra "território" no início do século XVIII, consultar: BLUTEAU, 1721: 128. Sobre o disciplinamento da população e o surgimento de uma nova concepção sobre o território, ver: FOUCAULT, 2008.
} 
estratégica com o serviço postal, visto como instrumento de comunicação, diretamente ligado ao incremento do comércio. Pode-se dizer, assim, que, ao enfatizar essa necessidade de que os domínios régios contassem com sistemas eficientes de integração entre as suas partes, D. Luís da Cunha afinava-se com mudanças de caráter mais amplo na percepção das relações entre a governação, a economia e o disciplinamento dos territórios. Todavia, como também se argumentará aqui, suas proposições relativas à conservação e ao governo dos domínios régios estavam em ressonância com um entendimento da razão de estado que ainda fincava suas raízes no terreno secular da cultura política corporativista do Antigo Regime.

O diplomata e o conselheiro

D. Luís nasceu em 1662, oitavo de uma prole de nove filhos, numa das famílias mais nobres de Portugal. Como outros poderosos de seu tempo, entretanto, não escapou de boatos relativos a uma suposta "impureza" de sangue, no caso por parte de sua mãe, D. Maria Manuel de Vilhena. Abílio Diniz Silva (2001: 29) chega a aventar a hipótese de tais suspeitas estarem na raiz tanto do fato de D. Luís por não mais voltar a Portugal depois de, no apagar das luzes do século XVII, ter saído do país, quanto de suas críticas à Inquisição. O certo é que seus familiares jamais encontraram obstáculos quando das provas necessárias à obtenção de títulos, cargos públicos e outras mercês, como o Hábito de Cristo, que ele mesmo recebeu em 1696, pouco antes de iniciar sua carreira na diplomacia. ${ }^{4}$

Seu pai, D. António Álvares da Cunha, senhor da Tábua, Trinchante da Casa Real, reunia a formação militar com a intelectual, tendo sido um dos fundadores da Academia dos Generosos, em cuja segunda fase o próprio D. Luís viria a exercer um importante papel. ${ }^{5} \mathrm{D}$. António foi membro da Royal Society de Londres e guarda-mor da Torre do Tombo, cargo que parece ter assumido não só pela distinção concedida, mas por um real interesse no estudo dos manuscritos, então guardados no castelo de São Jorge.

Crescido num ambiente em que as preocupações com a oratória e a poética eram importantes, D. Luís formou-se em Coimbra em Direito Canônico e com apenas vinte anos foi

\footnotetext{
${ }^{4}$ Para as informações biográficas apontadas neste artigo, ver: LEONZO, 1976; CLUNY, 1999; SILVA, 2001; FURTADO, 2013.

5 A Academia dos Generosos, fundada de acordo com o modelo da Academia de Paris, foi composta por vários dos nobres da época, dentre os quais se destacaram os condes da Ericeira e de Tarouca, com nomes importantes no cenário das letras, como D. Francisco Manoel de Mello e António de Sousa Macedo. A sua primeira fase encerrou-se em 1676 e, na segunda, o próprio D. Luís teve um papel importante, entre 1693 e 1696. D. Luís da Cunha ainda participaria, a partir de 1723, da Academia Real de História, fundada por D. João V três anos antes. Sobre o assunto, ver: FURTADO, 2010, p. 379.
} 
nomeado Desembargador da Relação do Porto, iniciando uma carreira favorecida tanto por sua origem nobre quanto por seus dotes pessoais. A sua trajetória posterior mostra um homem de elite, movendo-se entre os meandros da política e da administração de seu tempo, sem descurar de atividades menos pragmáticas, de caráter mais intelectual e mesmo mundano. Passou depois para a Relação de Lisboa, tendo sido designado desembargador extravagante da Casa de Suplicação em 1688 e provedor das capelas em 1694. Entre 1693 e 1696, participou do renascimento da Academia dos Generosos. Em abril de 1697 partiu como enviado extraordinário à corte de Londres, onde permaneceu até 1712.

Ali se convenceu da importância das questões econômicas para as relações internacionais e de que o comércio inglês estava em um ciclo de expansão, o que fazia da Inglaterra um agente importante no cenário mundial. Defensor da aproximação entre Portugal e aquele país, colocou-se, todavia, francamente contra o famoso Tratado de Methuen, em relação ao qual foi uma voz vencida. ${ }^{6}$ Nesse período londrino, tornou-se habitual conviva do pouco convencional salão da duquesa de Mazarino - exilada em Londres por causa dos seus “costumes muito livres" (SILVA, 2001: 40) - onde se discutiam questões filosóficas e literárias. Nesse ambiente, incrementou o contato com novas ideias, mercantilistas no plano econômico, valorizadoras do livre-arbítrio e da liberdade religiosa em um terreno mais

\footnotetext{
${ }^{6} \mathrm{O}$ tratado de Methuen (1703), celebrado entre Portugal e Inglaterra, foi também conhecido como "dos panos e dos vinhos". Nos termos convencionados por aquele instrumento, Portugal franqueava seu território aos tecidos ingleses, enquanto a Inglaterra liberava a entrada dos vinhos portugueses. A partir de sua assinatura, intensificaram-se as relações comerciais entre os dois países e, como consequência, a troca de correspondências relativas a esses negócios. Todavia, de acordo com os seus críticos, o tratado criou um fluxo comercial francamente deficitário para o país ibérico. Na concepção mercantilista, superávits nesse campo eram essenciais para garantir o processo de acumulação de riquezas. Assim, muitas das censuras ao tratado baseavam-se em acusações de que ele gerava um fluxo desfavorável a Portugal. Além de Cunha, o tratado teve entre seus adversários, ao longo do século XVIII, Alexandre de Gusmão, o Marquês de Pombal e o conde de Linhares, entre outros. Como consequência do déficit português, boa parte do ouro brasileiro teria escoado para a Inglaterra, ajudando a financiar a implantação do capitalismo inglês. $O$ interessante é que Methuen não era consenso nem mesmo entre os britânicos, entre os quais diversas vozes reclamavam que o acordo anterior, datado de 1654, teria sido bem mais vantajoso para os interesses de seus conterrâneos. Adam Smith, em passagem muito citada de A riqueza das nações, também criticou o tratado, encarado por ele como típico instrumento mercantilista, portanto maléfico em relação às forças do livre-mercado. Apesar de todas as críticas que motivou, o acordo somente foi extinto em 1842. Diversos autores buscaram matizar depois essas visões históricas a respeito de Methuen, apesar de, geralmente, apontarem prejuízos causados por ele à economia portuguesa. Nelson Werneck Sodré (1965: 15-53), por exemplo, fez longa explanação sobre o tratado, mas, apesar de considerar irrefutáveis os seus efeitos negativos sobre as manufaturas, a agricultura e a balança comercial lusas, defendeu que não se poderia creditar-lhe todo o atraso industrial e econômico do país. Felipe de Alvarenga Batista (2014) procurou compreendê-lo do ponto de vista da conjuntura internacional contemporânea à sua assinatura e do contexto de outros tratados firmados na época. Também sobre Methuen, pode-se consultar um texto já clássico: AZEVEDO, 1947. Especificamente sobre as posições de D. Luís da Cunha sobre o assunto, ver: SILVA, 2001; SILVA, 2003.
} 
filosófico e político. ${ }^{7}$ Mais tarde, entre abril de 1712 e maio de 1716, foi embaixador na Holanda, onde participou diretamente das negociações dos Tratados de Utrecht (1713-1715), que puseram fim à Guerra de Sucessão Espanhola e garantiram à coroa portuguesa a posse das terras compreendidas entre o Oiapoque e o Amazonas, bem como do território de Sacramento. Esses acordos consolidaram, do ponto de vista geopolítico, a presença lusa na América meridional e deram um passo largo para uma transformação crucial do império, marcada pela afirmação da centralidade e importância das terras brasileiras.

Nos anos seguintes, D. Luís se desdobraria entre Londres, Hanover, Haia, Madri, Cambrai, Paris e Bruxelas, lugares onde privou com a nata da diplomacia europeia e manteve contato com artistas, empenhando-se no envio de obras de arte para o Reino. Encerrou sua vida em Paris, como ministro de Portugal naquela praça. Morreu em 9 de outubro de 1749, depois de uma carreira, que começara no reinado de D. Pedro II e acompanhara quase integralmente o longo governo de D. João V (1710-1750).

Esse breve excurso biográfico, certamente bastante lacunar, dá uma ideia da grande experiência diplomática e mundana acumulada por D. Luís. Permite vislumbrar também o ambiente em que se desenvolveu uma concepção de mundo surgida não de elucubrações teóricas, mas dos embates cotidianos dessa militância diplomática, em que as questões políticas e econômicas tinham um papel central. Foram lançadas, assim, as bases de um pensamento eminentemente pragmático.

Algo que certamente poderia interessar a qualquer historiador preocupado com a importância não da ação diplomática, mas do pensamento político-administrativo de D. Luís da Cunha é até que ponto suas obras realmente foram conhecidas e repercutiram durante sua vida e nos anos seguintes. Suas Memórias, na realidade uma monumental história política da Europa do início do século XVIII, permaneceram na forma de manuscritos. Sua gigantesca correspondência, dispersa em vários arquivos e apenas parcialmente publicada até hoje, teve circulação restrita, dada a própria natureza desse tipo de escrito. Dentre as suas cartas, a de maior repercussão, aquela conhecida como Testamento Político, somente seria impressa no início do século XIX. As Instruções políticas apenas chegariam a um público mais amplo em 1929, em edição da Universidade de Coimbra.

Assim, não é possível conceber que suas ideias tenham tido uma ampla publicidade no início do século XVIII, quando o autor as registrava, apesar de haver notícias da disseminação

\footnotetext{
7 O que não o impediu de receber diretamente do Papa Clemente XI o arcediagado de Évora, "[...] em recompensa da coragem que demonstrara na defesa do culto católico [...]” (SILVA, 2001: 48; 121).
} 
de alguns de seus textos em cópias manuscritas, numa prática relativamente comum naquele tempo. O Testamento político, por exemplo, teria chegado a circular desse modo (LEONZO, 1976: XVI). De acordo com Abílio Diniz Silva (2001: 169) seus manuscritos eram disputados pelas famílias aristocráticas no início do século XVIII, de modo que há várias cópias deles em diversos arquivos, com os ex-libris de diferentes casas nobres. Das Instruções, por exemplo, existem diferentes exemplares na Biblioteca do Palácio da Ajuda e no Arquivo da Casa Palmela.

D. Luís da Cunha não era, todavia, um publicista e um polemista, mas um homem de gabinete, um político e diplomata envolto com as redes de poder de seu tempo e que falava para um grupo bastante restrito, embora escolhido. Sua estratégia parece ter sido, assim, a de debater com e convencer alguns poucos eleitos, homens de governo e formadores de opinião, capazes de realmente interferir nos rumos da administração, ainda que seus escritos, às vezes, tenham atingido um público um pouco mais amplo. E é esse o caso dos dois textos aqui abordados.

\section{As Instruções políticas e os Correios}

As Instruções foram escritas a pedido de Marco Antônio de Azevedo Coutinho, discípulo de D. Luís da Cunha, que, em 1736, encontrava-se em Londres com a missão de negociar uma possível ajuda inglesa, caso Portugal fosse invadido por forças espanholas. Coutinho estava em vias de assumir a Secretaria de Negócios Estrangeiros. A pretexto de encontrar-se receoso com sua falta de preparo diante dos desafios da nova função, escreveu sucessivas cartas ao mestre, solicitando-lhe conselhos. Em resposta a esse apelo, D. Luís começou a redigir as Instruções que, no entanto, jamais seriam enviadas ao seu destinatário original, mas sim a um sobrinho do autor, quase seu homônimo, D. Luís da Cunha Manuel (SILVA, 2001: 137-140). Esse outro D. Luís da Cunha seria secretário de Estado dos Negócios da Guerra e Estrangeiros no período de D. José I, entre 1756 e 1775. Assumiu o cargo justamente quando Pombal, de quem sempre foi próximo, passou a ocupar a Secretaria de Estado dos Negócios do Reino.

De acordo com Magalhães (2004: s.p.), essa alteração de rumos quanto ao destinatário da carta pode ter decorrido de o próprio Cunha ter visto as suas ideias como perigosas ou de difícil implantação, motivo por que resolveu deixá-las em um círculo mais restrito. Júnia Ferreira Furtado (2013: 29-30) lembra que D. Luís mesmo tivera esperanças de vir a assumir 
a Secretaria de Negócios Estrangeiros. Não seria descabido, embora de difícil comprovação, pensar que alguma eventual frustração decorrente desse fato possa ter interferido na sua decisão posterior de mudar o destinatário do texto. Na carta que encabeça o material originalmente escrito para Coutinho, o nosso autor mesmo justifica a mudança de outro modo, ao dizer que "[...] comecei a conceber que fora com espírito de lisonja, e não de necessidade, que Marco António me pedia que o instruísse [...]” (CUNHA, 2001: 174). Diz ainda que “[...] ele se devia aproveitar das minhas ideias como minhas, ou como suas [...]" - no primeiro caso, “[...] as suprimiria, pois desta sorte não the granjeariam o crédito que com elas devia procurar [...]", ao passo que, no segundo, “[...] não ousaria promovê-las, por serem muito livres, de que se seguiria a inutilidade do meu // trabalho [...]" (CUNHA, 2001: 174).

Transparece, na redação das Instruções, a preocupação em equilibrar-se entre uma análise objetiva da realidade e os melindres de sua época, marcada pelos preconceitos contra os cristãos novos e por disputas no ambiente cortesão. De acordo com Silva (2001: 145), D. Luís da Cunha percebeu que, para respeitar suas ideias e, ao mesmo tempo, não enfrentar a censura da corte e da inquisição, deveria optar pela

[...] demonstração da pura evidência das coisas - isto é: não era ele quem tirava as conclusões, mas uma força imanente e superior, a lógica da razão que conduzia à evidência. Subtilmente, o sujeito das suas afirmações deixava de ser ele, mas uma terceira entidade, abstracta, chamada "evidência da razão de Estado". Era ela que comandava as suas afirmações, desde a análise da situação em que se encontrava Portugal ao enunciado das necessárias reformas, e dos inevitáveis remédios. (grifo meu)

É guiado por essa razão de estado que Cunha escreve. Diga-se que o termo, no caso, não tem a mesma acepção que na atualidade, quando pode significar até mesmo uma contravenção à legislação ordinária, em nome do bem comum ou da manutenção do poder. $\mathrm{O}$ conceito, no caso, é o mesmo expresso em importantes tratados sobre a arte de governar que tiveram forte influência sobre o pensamento político português da época. Refere-se, assim, ao “[...] conhecimento de meios que se alcançam pelo Conselho, industriosamente guiado ao bom governo do Senhorio [...]" (PRADO, 1617: 3) ${ }^{8}$ e ao "[...] conhecimento dos meios adequados para fundar, conservar e ampliar um Domínio [...]" (BOTERO, 1589: 1). ${ }^{9}$ No texto

\footnotetext{
${ }^{8}$ No original: “[...] conocimiento de médios que se alcançam por el Consejo, industriosamente guiado a 1 buen gobierno d’1 Señorio, à la diferencia de los umores, aprovechan, ò dañan los ejemplos, que mostraron malos, ò Buenos sucesos i despues se aplican por su semejança [...]”. Tradução livre do autor.

${ }^{9}$ No original: "Ragione di Stato si è notitia d'mezi, atti à fondare, conservare, $\&$ ampliare um Dominio [...]". Tradução livre do autor.
} 
de Cunha, o conceito transparece em passagens como a seguinte, em que, a ecoar Botero, o autor discute a relação entre o príncipe e o estado, aqui entendido como "domínio", "reino" e não como essa entidade separada da sociedade civil que a palavra passaria a significar mais tarde: “[...] qual seja o mais próprio para a conservação e aumento de um Estado: se empobrecer o príncipe para que o povo seja rico, ou se enriquecer o príncipe para que o povo seja pobre?" (CUNHA, 2001: 281). A razão de estado é justamente, nos escritos da época, aquela que aponta o que é apropriado para esse objetivo de manutenção e incremento do domínio régio, tendo como horizonte a busca do bem comum.

Nesse aspecto, a obra de D. Luís da Cunha não deixa de se alinhar com diversos tratados produzidos em Portugal ao longo do século XVII e no início do XVIII, mas, diferentemente de outros textos de instruções ou conselhos aos governantes, não se concentra majoritariamente em recomendações de caráter geral ou exemplos retirados da mitologia, da Bíblia ou da história de outras terras. ${ }^{10}$ Enfrenta, de forma decidida, questões bastante contemporâneas e próprias do reino de Portugal, não se furtando à denúncia de mazelas e fraquezas.

As Instruções começam apontando o que o autor considera o modelo de um bom governante e prosseguem com o suposto risco de perda de independência de Portugal. Fundamentam, assim, a necessidade de mudanças, dentre elas o necessário aumento das riquezas nacionais e a superação de desvantagens estratégicas que o país possuiria, por ser pequeno e pouco povoado. Para tanto, propõem uma série de medidas: redução dos privilégios; ordenação do consumo de luxo; renovação da política manufatureira; revisão do Tratado de Methuen; constituição de companhias de comércio colonial, melhoria da infraestrutura de transporte, entre outras. A mais ousada seria Portugal assumir-se como um império ultramarino, ao transcender as suas fronteiras europeias e mudar a corte para o Rio de Janeiro (CUNHA, 2001: 366-372). Tal proposta retoma antigas ideias do padre Vieira e mostra a clarividência de Cunha diante da "virada atlântica", o deslocamento do eixo principal do império português para o Atlântico Sul.

A despeito da ousadia das propostas, o pensamento de Cunha move-se, no caso, dentro de um quadro traçado pela concepção corporativista da Segunda Escolástica e compreende a economia do país como uma extensão da Casa Real. Não é, obviamente, um liberal que fala. É um homem do Antigo Regime, ainda com uma visão patrimonialista das forças econômicas.

\footnotetext{
${ }^{10}$ Entre esses outros textos, podem-se citar: Arte de reinar, de Antônio Carvalho de Parada (1644), Suma política, de Sebastião César de Meneses (1649), e o Tratado político, de Rocha Pita (1713)
} 
Não é objetivo aqui alongar-se na demonstração dessas afirmações, tendo em vista a finalidade restrita do artigo, voltado para a abordagem que Cunha fez do serviço postal. Mas a própria leitura do trecho em que o assunto é tratado não deixará muitas dúvidas a respeito do que aqui se afirma.

A passagem em que Cunha trata dos correios aparece entre proposições de medidas destinadas para aumentar as receitas e reduzir as despesas do reino. Como o fragmento é relativamente curto, será transcrito aqui na íntegra:

Esta ideia me inspira outra realmente lucrativa para Sua Majestade, e vem a ser: tomar a si o correio e arrendar a sua produção: assim o pratica el-rei de França e el-rei de Inglaterra, de que se tiram grandíssimas somas. É verdade que os predecessores do correio-mor, conforme ouvi, compraram este ofício ao senhor rei Dom João o IV; mas quantas vezes terão os seus sucessores quatropiado $^{11}$ o seu capital? Isto consideraram os ministros de Filipe V, estando eu em Madrid, para tirarem ao conde // de Ognate ${ }^{12}$ o mesmo emprego, sem que se lhe desse algum equivalente. Ainda que o príncipe de La Tour ${ }^{13}$ conserva o correio do País-Baixo, contudo, todas as vezes que a corte de Viena necessita de cem mil florins, o ameaça de lho tirar, e é necessário que com eles concorra para o não perder, o que de muita boa vontade faz, porque os tira de portes de cartas que levanta, sendo os particulares os que por fim de contas pagam as custas. (CUNHA, 2001: 351)

A preocupação, no caso, é antes com o aumento das rendas da coroa do que com uma possível ineficiência de um serviço de comunicação extremamente importante para o "império de papel” que era Portugal na época. ${ }^{14}$ A concepção patrimonialista emerge na passagem em que o autor aconselha ser desejável o rei " [...] tomar a si o correio e arrendar a sua produção [...]", dando como exemplos os casos de França e Inglaterra. O modelo que Cunha tem em mente é, de modo claro, o dos contratos feitos pela coroa para a gestão de determinados monopólios, arrecadação de impostos e exploração de minas, entre outras atividades.

Do ponto de vista histórico, o nosso autor comete aqui dois equívocos. O primeiro tem a ver com a história do próprio serviço postal português. A venda para os Mata do ofício de correio-mor do reino, detentor do monopólio do tráfego de cartas em terras lusas, não acontecera no reinado de D. João IV, mas antes, em 1606, sob Felipe II (III de Espanha). A do

\footnotetext{
${ }^{11}$ De acordo com Silva (2001: 351), "barbarismo, por 'quadruplicado"”.

${ }^{12}$ Forma afrancesada do nome do Conde de Oñate.

${ }^{13}$ Silva (2001: 351) anota que se trata de personagem "não identificado". Todavia, trata-se de possível referência à família dos Thurn und Taxi (originalmente, Tasso, da Lombardia), primeiros donos do monopólio postal na Espanha e nas terras do Sacro-Império, responsáveis por estender a tecnologia das postas à grande parte da Europa. Ver, nesse aspecto, entre outros: GAZAGNADOU, 2013: 103-104.

${ }^{14}$ Busco a expressão "império de papel” em: HESPANHA, 1994: 291.
} 
correio-mor das cartas do mar, cargo comprado pela mesma família, responsável pela internação de todas as correspondências recebidas por via marítima e mais especificamente pelas trocas com as conquistas do Atlântico sul, materializou-se em 1657, no período da regência de D. Luísa de Gusmão, durante a minoridade de Afonso IV. ${ }^{15}$

O segundo equívoco refere-se ao modo como se dera, no final do processo, a retomada do ofício de correios pela coroa espanhola, anteriormente também em mãos de particulares. $\mathrm{O}$ cargo ficara em mãos das famílias Tassis e Vélez de Guevara desde o século XVI. Retomado por Felipe V em 1706, mediante indenização aos Guevara, fora, de fato, inicialmente arrendado ao marquês de Monte Sacro e depois a Juan Francisco Goyeneche, que o exerceu até 1717. Nesse ano, entretanto, o serviço passou a ser administrado pela coroa, que passou a receber diretamente suas tarifas. O modelo finalmente adotado foi, assim, diferente do arrendamento preconizado por Cunha, mas semelhante ao que seria instituído no império português no final do século XVIII, durante as reformas de D. Rodrigo de Souza Coutinho. Cunha invoca, como testemunha ("estava eu em Madri”), o acontecido em 1706, quando a coroa espanhola efetivamente retoma o serviço das mãos do conde Oñate (da família dos Guevara), mas não parece ter ciência das alterações posteriores, que já não tinham um aspecto propriamente patrimonialista, mas apontavam, ainda que timidamente, para uma nova concepção de administração pública, que somente começaria a ganhar força na Espanha durante o período bourbônico. ${ }^{16}$

O equívoco sobre o período de venda do correio português é sinal de que D. Luís não chegara a debruçar-se a fundo sobre o caso, embora tivesse certeza sobre o acerto da medida e a oportunidade do que propunha. Por isso, talvez tenha minimizado as dificuldades jurídicas de uma operação desse tipo, ao considerar que a coroa portuguesa poderia simplesmente retomar o monopólio, considerando que ele já fora pago com os ganhos anteriores do correiomor. É possível perceber mesmo uma visão quase maquiavélica, em que os fins justificam os meios, na passagem em que lembra que

[...] todas as vezes que a corte de Viena necessita de cem mil florins, o ameaça de lho tirar, e é necessário que com eles concorra para o não perder, o que de muita boa vontade faz, porque os tira de portes de cartas que levanta, sendo os particulares os que por fim de contas pagam as custas. (CUNHA, 2001: 351)

\footnotetext{
${ }^{15}$ No que concerne à venda dos ofícios de correio-mor aos Mata, ver, entre outros: SOBRAL NETO, 2005; MACHADO, 2008.

${ }^{16}$ No que tange à reapropriação dos correios hispânicos pela coroa no início do século XVIII, ver, entre outros: PÉREZ SARRIÓN, 2012.
} 
A incipiência da reflexão do autor sobre os correios transparece em outro aspecto. Apesar de já ponderar sobre a possibilidade de transferência da capital do império português para a América, D. Luís da Cunha ainda não consegue pensar sobre a importância estratégica do serviço postal para o funcionamento da administração entre os dois lados do Atlântico, visão que seria de extrema importância na implantação do serviço postal marítimo pela monarquia espanhola na metade do século XVIII. ${ }^{17}$

Esse primeiro vislumbre de D. Luís sobre a questão do correio, entretanto, ganharia mais corpo no Testamento político, como se verá.

\section{O Testamento político e os Correios}

O Testamento político é uma longa carta escrita ao futuro rei D. José I, entre 1747 e 1749, quando ainda se encontrava vivo D. João V. É, de certo modo, o canto de cisne do velho diplomata, que morreria naquele último ano. $\mathrm{O}$ documento foi produzido, com o intuito de aconselhar o futuro monarca de Portugal, por alguém que lembra ser o mais antigo ministro em serviço e que se dirige ao príncipe

[...] não para de lhe pedir algum prêmio pelos meus serviços, mas somente para pôr na sua real presença quais são os meus sentimentos com a liberdade que o dito senhor não só me permitiu, mas expressamente me ordenou; e assim me aproveito dela para quando $\mathrm{V}$. A. tomar, com a felicidade que the desejo, as rédeas do governo dos seus reinos e dilatadas conquistas, para o bem de seus fiéis vassalos [...] (CUNHA, 2010: 601) ${ }^{18}$

Bem no princípio do texto, o autor declara ainda que, preferencialmente, não procurará se servir de exemplos tirados da história, mas daquilo que viu praticar em algumas das principais potências europeias, "[...] ainda que nem todas se possam seguir pela diferença dos climas, dos governos, dos interesses, dos tempos, e pelos diversos gênios das Nações [...] (CUNHA, 2010: 601). Nessa preferência pelas experiências do presente, mais que pelas do passado, D. Luís parece se aproximar de D. Sebastião César de Meneses, que, em sua Suma

\footnotetext{
${ }^{17}$ Quanto à implantação dos correios marítimos espanhóis, ver: BELOTTO, 1971; ARANEDA RIQUELME, 2015.

${ }^{18}$ Para este trabalho, foram utilizadas três diferentes edições do Testamento político. A primeira é a pioneira edição em livro, da Imprensa Régia, datada de 1820 e disponível para descarga no Google Livros. A segunda é a edição brasileira da editora Alfa-Ômega, de 1976, revisada e introduzida por Nanci Leonzo. A terceira é a que integra a antologia Conselhos aos governantes, publicada pelo Senado Federal. Para as transcrições, optei por usar essa última, pois a ortografia empregada é a mais próxima da atual. Da edição da Alfa-Ômega, utilizei informações contidas na introdução.
} 
política, num confronto com as lições de Botero e de boa parte da tratadística política do Antigo Regime, disse: “[...] se os mortos ensinam com o que escrevem, os vivos ainda são melhores mestres, pelo que explicam e declaram a quem os ouve e lhes pergunta [...]" (MENESES, 2010: 533).

Vários dos temas e preocupações do Testamento lembram as Instruções, em um texto bem mais enxuto. Por exemplo, em ambos emergem as críticas à Inquisição e às consequências do Tratado de Methuen, bem como a importância dada às comunicações internas do país e às manufaturas, bem como à necessidade de incrementar o povoamento dos domínios régios. A comparação do povo com o sangue do reino, afetado por várias sangrias, aparece nas duas cartas, ainda que com pequenas diferenças. As metáforas em torno do governo da família e do corpo do Estado também assumem um papel importante no Testamento, sempre de acordo com uma concepção de governo inequivocamente afinada com uma cultura política que é a do Antigo Regime.

Assim, depois de alguns conselhos sobre as adequadas conduta e postura de um príncipe, D. Luís destaca que "[...] um rei não difere [...] de qualquer outro pai de famílias mais que em o ser de muitas e não de uma só [...]" (CUNHA, 2010: 609). A partir dessa constatação, o autor aborda aquelas que considera serem as cinco obrigações de um bom pai (e por extensão de um bom príncipe): dar competente sucessão à sua casa; ter bem regrado o serviço dela "[...] para que cada qual dos seus domésticos faça as funções que lhe competem, conforme a graduação dos seus empregos [...]" (CUNHA, 2010: 610); evitar dissenções que perturbem a economia dessa casa; não tê-la endividada e cheia de demandas com terceiros; finalmente, visitar as suas terras para ver se estão bem cultivadas e se não há desvios nelas.

É ao tratar dessa última e importante obrigação do bom pai de família que Cunha elenca as mazelas que, a seu ver, assolam Portugal, fazendo com que o reino seja um corpo doente e necessitado de cuidados médicos:

Se, pois V.A. quiser dar uma volta aos seus reinos, observará em primeiro lugar a estreiteza dos seus limites, à proporção do seu vizinho. Achará, não sem espanto, muitas terras usurpadas ao bem comum, outras incultas, muitíssimos caminhos impraticáveis, de que resulta faltar o que elas podiam produzir, e não haver entre as províncias a comunicação necessária para o seu comércio: achará muitas e grandes povoações quase desertas, com suas manufaturas arruinadas, perdidas e extinto totalmente o seu comércio; achará que a terça parte de Portugal está possuída pela Igreja, que não contribui para a despesa e segurança do Estado [...]; e, enfim, achará que o seu reino não é povoado como pudera ser, para prover de gente as suas largas e ricas conquistas, de que separadamente tratarei. (CUNHA, 2010: 614)

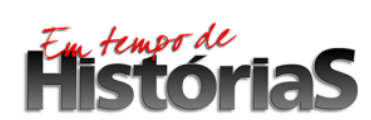


É interessante lembrar que, se D. Luís da Cunha indica ao soberano visitar os próprios domínios para reconhecer-lhes as mazelas, seu próprio diagnóstico é feito à distância, já que não voltava ao reino há décadas. Apesar dessa falta de proximidade física com o enfermo, o autor - sempre a guiar-se pela metáfora da monarquia como um corpo - erige-se em médico. Declara então que “[...] indico os remédios que me oferecem, não aprendidos na escola de Avicena, mas nas observações que tenho feito em semelhantes enfermidades [...]" (CUNHA, 2010: 614). É ao tratar de tais soluções e de uma das doenças que assolam o corpo do reino, a precariedade das comunicações, tão danosa ao comércio, que ele aborda o mau estado dos caminhos:

Acresce, como deixo dito, que V. A. acharia impraticáveis muitos caminhos, de que em parte provém a decadência do comércio interior do reino, não se podendo, ou sendo muito difícil, transportar as fazendas de umas para outras províncias, o que porém se poderia remediar, obrigando os moradores circunvizinhos a que por seus turnos trabalhassem a fazer mais cômodas as ditas estradas, pois da frequência da sua passagem sempre tirariam alguma conveniência; bem sei que em algumas partes seria inútil o seu trabalho para dar a comodidade dos carros. (CUNHA, 2010: 627)

Os caminhos são vasos de circulação do sangue do reino. Embora não trace uma ligação explícita entre as questões das estradas e do correio, uma segue naturalmente a outra, numa construção lógica que traz ao texto o exemplo do serviço postal dos Países Baixos:

De Haia para Amsterdã e de Amsterdã para Haia, além do correio ordinário, partem todos os dias dois carros de posta cobertos e capazes de receber passageiros, e um grande barco para a fazenda que se quer transportar. Da mesma Haia para Delft, e de Delft para Haia parte um barco todas as meias horas e de três em três parte outro para Roterdã e para Leide da mesma sorte que destas cidades e de outras partem para Haia, além dos barcos mercantes; tal é a frequente correspondência e tal o comércio que entre elas circula. (CUNHA, 2010: 628)

Há uma sutil, porém notável, diferença entre essas passagens e aquela em que o autor tratara do mesmo assunto nas Instruções. Deve-se observar que, naquele texto mais antigo, o trecho sobre o correio insere-se claramente no plano de redução de despesas e incremento de receitas do Estado e não em uma estratégia voltada para a melhoria das comunicações do reino, apesar de se seguir a também uma reflexão sobre a necessidade de se recuperarem as estradas a bem do comércio. Há, no Testamento, outra percepção relativa ao serviço postal, visto não mais como uma mera fonte de arrecadação, mas como um instrumento estratégico 
de governo. D. Luís, baseado no que acontecia em outras regiões da Europa, estabelece um vínculo direto entre os serviços postais, os transportes e o desenvolvimento do comércio.

Depois do exemplo colhido no estrangeiro, o autor aborda a maneira como entendia que o assunto poderia ser tratado em Portugal. Se, nas Instruções, o conselheiro apontara uma solução “[...] realmente lucrativa para Sua Majestade [...]", mas bastante extrema, que vinha a ser: “[...] tomar a si o correio e arrendar a sua produção [...]” (CUNHA, 2001: 351), a posição é bem mais prudente no Testamento. O que se aconselha é que se tratassem inicialmente com o correio-mor aprimoramentos no serviço, como a criação de casas de posta e o fornecimento de cavalos para o envio de correspondências mais urgentes:

Para darmos alguma ao nosso, dissera que este negócio se tratasse com o correio-mor, propondo-lhe que devesse ter em cada lugar notável uma boa casa de posta, onde sustentasse certo número de bestas de carga, destinadas a fazerem os mesmos serviços dos carros, como também cavalos de posta para que deles se possam servir os mercadores, que necessitarem de mais prontos avisos; pois ninguém crerá que entre duas cidades de tão grande comércio, como são Lisboa e o Porto, não podem os negociantes ter resposta senão em quinze dias, de que o mesmo correio-mor pode tirar o seu proveito [...] (CUNHA, 2010: 628)

D. Luís da Cunha não se contentou apenas em sugerir como o serviço postal deveria ser administrado pelo correio-mor, mas foi além. Caso o titular do ofício não se interessasse em promover as melhorias necessárias, o soberano deveria partir para ações mais extremas:

[...] e quando não lhe convenha, poderá S. Majestade tirar-lhe o ofício, pagando-lhe a soma, que por ele deram os seus antecessores, pelo valor da moeda que então corria, ou assinar-lhe no rendimento do dito correio uma conveniente pensão, pois que dela tantas vezes tem tirado os seus interesses. Isto mesmo se praticou com o marquês de Torcey, porque as postas pertenciam aos secretários de Estado dos Negócios Estrangeiros. El-rei de Castela o tirou ao conde de Ugnati sem esta circunstância. França e Inglaterra se servem deste grande fundo. (CUNHA, 2010: 628)

Tal mudança de posição pode ter decorrido de, com a passagem dos anos, D. Luís ter uma ideia mais clara das dificuldades jurídicas de a coroa se apossar do sistema postal, haja vista as condições férreas em que se dera a venda do ofício para a família dos Mata. ${ }^{19}$ Prefere, desse modo, apontar a ineficiência do serviço controlado pelos particulares (quinze dias entre Lisboa e o Porto!) e propor medidas que, a seu ver, poderiam melhorar a qualidade dos prazos

\footnotetext{
${ }^{19}$ Sobre as condições de venda do correio-mor para a família Mata e a patrimonialização do ofício, ver:
} SALVINO, 2015b. 
de entrega. Apenas se tais providências não interessassem ao correio-mor, deveria o rei retomar o monopólio, ainda assim contra o devido pagamento, em respeito aos direitos dos Mata. Essa mudança de foco, que passa a privilegiar a busca de uma boa qualidade do serviço, torna ainda mais claro que, neste caso, o objetivo primeiro das propostas era garantir uma comunicação mais rápida e eficiente nos domínios reais, uma ligação adequada entre as partes geográficas que compunham os domínios - uma visão que poderíamos chamar de geopolítica, portanto.

Não que tenha sido esquecida a possibilidade de incrementar receitas. Se fossem mais bem regulados os preços, assim como se as correspondências vindas das conquistas fossem obrigadas a circular pelas postas, o serviço poderia ser arrendado com "considerável vantagem da sua real fazenda". D. Luís, porém, mostra-se cônscio de que o correio português não teria condições de gerar os mesmos ganhos de seus congêneres em terras com comércio mais desenvolvido:

Presentemente as províncias de Holanda o cederam ao novo Stathouder, que generosamente o aplicou ao público. Não quero dizer que o nosso correio produzirá tão grandes somas, porque nem temos tantas correspondências, nem tanto comércio; mas no caso de serem melhor [sic] regulados os portes das cartas e mandando-se que todas as que vêm das conquistas vão ao correio, estou bem certo que S. Majestade poderá arrendar o dito ofício com muito considerável vantagem da sua real fazenda, ajustando as condições que parecerem ser mais necessárias para que as correspondências, assim domésticas, como estrangeiras, sejam regulares. (CUNHA, 2010: 628)

A menção às correspondências oriundas das conquistas é uma novidade no Testamento em relação às Instruções. Há dois pontos a ressaltar no que se refere a esse aspecto. Primeiro há de se observar que D. Luís se refere a elas apenas como um elemento para aumentar a arrecadação do correio. Deveria supor, assim, que esse tráfego fosse relativamente significativo, mas não parece dar uma atenção diferenciada à importância de tais cartas como meio de comunicação entre Lisboa e as cidades e vilas de uma terra longínqua como o Brasil, que se tornara tão vital para o império, notadamente depois da descoberta das minas de ouro. Não estabelece qualquer relação entre elas e as preocupações geopolíticas que manifesta em outros escritos, dentre eles as próprias Instruções. No Testamento, o autor não voltou à ideia de transferência da corte para o Rio de Janeiro, proposta naquele outro texto. Mesmo assim, considerada a relevância da conquista sul-americana para o império, a preocupação com as comunicações entre os dois lados do Atlântico deveria ter um papel estratégico, para a qual D. Luís não parece atentar. 
Depois, ao se referir tão somente às "cartas que vêm das conquistas", o autor parece considerar não haver problemas com relação àquelas que faziam o caminho inverso. De acordo com Rodolfo Garcia (1975: 131), em 1733, D. João V ordenara que nenhuma pessoa, de qualquer condição, nem mesmo os capitães dos navios, poderiam trazer "cartas fora da arrecadação" para o Brasil. O correio-mor tinha, desse modo, confirmado o monopólio dessas trocas. Ainda que o sistema fosse permeável, sujeito a inevitáveis contrabandos fora do sistema oficial, havia melhores condições para o controle do tráfego entre o reino e a América do que no sentido contrário, dada a implantação do correio-mor das cartas do mar desde 1657, com a obrigação nominal de regular esse fluxo. Por outro lado, a falta de assistentes do correio nas conquistas para cuidar do embarque das cartas ou de uma normatização sobre quem, na ausência deles, poderia desempenhar tal papel, certamente fazia do monopólio ultramarino letra-morta em tal segmento. As tentativas de implantação do ofício de assistente do correio-mor nas praças litorâneas da América portuguesa foram várias, entre 1663 e 1738, mas sempre encontraram fortes obstáculos nas Câmaras locais, que viam na novidade apenas um custo extra, quando não uma tentativa de controle indevido. ${ }^{20}$ Mesmo que à distância, D. Luís da Cunha parecia ciente desses problemas e dessa deficiência no sistema de arrecadação.

O diplomata reclama também dos prazos praticados pelo correio em terras do reino. Faz recomendações de que sejam instaladas casas de correio que servissem como estações de muda nos locais que as necessitassem. O sistema de postas, todavia, fora implantado em Portugal desde o século XVI, e, ao longo do governo de D. João V, adotaram-se diversas medidas para reforçá-lo. ${ }^{21}$ Documentos do início da segunda metade do século XVIII - o Roteiro terrestre de Portugal, incluído em Mapa de Portugal antigo e moderno, de João Baptista de Castro (1762-1763), bem como a Notícia individual dos correios de que se servem os reinos de Portugal e Algarve, de Pedro Nolasco dos Reis, parte do Portugal SacroProfano, de Paulo Dias Niza (1768) - dão conta de uma rede de correios bastante sofisticada, a cobrir a maior parte das terras portuguesas, com frequências que dependiam da densidade populacional e econômica. ${ }^{22}$ Assim, aparentemente, os eventuais problemas de que poderia padecer o correio não eram a falta de normatização sobre as postas, ou insuficiências na designação de assistentes nas várias localidades, como parecia pensar Cunha. Poderia haver

\footnotetext{
${ }^{20}$ Sobre a resistência das Câmaras brasileiras às designações de assistentes de correios, ver: MACHADO, 2008; SALVINO, 2015a.

${ }^{21}$ Sobre as medidas adotadas pela coroa para confirmar e fortalecer o monopólio do correio-mor na primeira metade do século XVIII, ver: SALVINO, 2015a.

${ }^{22}$ Sobre esse assunto, ver CARVALHO, 2005.
} 
falhas na normatização mais operacional das postas ou na fiscalização do serviço ou os prepostos designados não cumprirem de fato as suas funções, mais interessados nas benesses do ofício do que em suas obrigações. Para piorar a situação, não se deve esquecer a precariedade das estradas, questão apontada pelo próprio D. Luís da Cunha, já que não há de se conceber os mensageiros conseguindo mover-se mais rápido do que as vias poderiam permiti-lo. Todavia, quaisquer que possam ter sido os motivos, há outras evidências históricas dessa morosidade dos correios portugueses, de modo que as reclamações de nosso autor parecem ser pertinentes, ainda que ele possa errar no receituário de possíveis soluções.

\section{Considerações finais}

Do exposto até aqui, é possível reter que, embora tenha se tratado de um assunto quase marginal nos escritos de D. Luís da Cunha, a discussão sobre o correio mostra que o diplomata era bastante atento aos problemas de seu tempo, além de dar pistas interessantes sobre as bases de seu pensamento. Embora propusesse soluções para o futuro e apresentasse novas ideias, D. Luís estava, evidentemente, movendo-se nos limites da cultura política de seu tempo, evidenciada, entre outros sinais, nas metáforas do corpo e da casa para explicar o funcionamento do governo e da razão de estado. O seu era um pensamento eminentemente pragmático, voltado para fins bastante tangíveis, como o incremento do comércio, objetivo último de sua preocupação com a melhoria das comunicações no Testamento. É notável que um homem com percepção geopolítica tão clara e mesmo visionária não tenha se debruçado sobre o papel da comunicação escrita para a governação ultramarina no caso de um império tão marcado pelas distâncias quanto o português. Todavia, ao sugerir que a coroa adotasse medidas para o desenvolvimento dos negócios e ao alargar, desse modo, os limites da oikonomia ("administração da casa") régia, encaminhando-a para o terreno do político, da preocupação com o bem estar da república, o seu pensamento inseria-se num movimento mais amplo de transformação do papel da própria monarquia, que ganhava força ao longo do século XVIII. Propunha, assim, um campo de atuação do soberano que ultrapassava já “[...] os limites de uma concepção jurisdicionalista do poder [...], as fronteiras da "[...] actividade real tendente a harmonização de esferas jurídicas alheias [...]”, típica da monarquia corporativa, e adentrava o terreno de uma ação mais "econômica" e de "boa polícia", para recuperar expressões usadas por António Manuel Hespanha (1994: 182) para descrever essa mudança. 
Segundo Abílio Diniz Silva (2001: 169), no espólio de D. Francisco Inocêncio de Souza Coutinho, pai de D. Rodrigo de Sousa Coutinho, havia manuscritos de D. Luís da Cunha. O futuro ministro de D. Maria I e D. João VI manifestou por carta ao secretário do pai preocupação com esses papeis, o que mostra o conhecimento que ele tinha deles e o respeito que lhes devotava. É interessante lembrar que foi justamente D. Rodrigo quem conduziu o processo de retomada pela coroa dos serviços postais e a sua posterior reestruturação, entre 1797 e o princípio do século seguinte. Afirmar taxativamente que, no caso específico da reforma dos correios, ele tenha se inspirado nas ideias das Instruções ou do Testamento político pode ser precipitado, mas é tentador pensar que o arguto "oráculo da geopolítica portuguesa" possa ter deixado mais essa semente, que germinaria apenas quase cinquenta depois de sua morte.

\section{Referências bibliográficas}

\section{Fontes primárias}

BOTERO [Benese], Giovanni. Della ragion di stato. Venetia, 1589. Disponível para download em: Google Livros. Acesso em: 20/05/2016.

BLUTEAU, Raphael. Vocabulário português e latino... [v.9] Lisboa: Oficina de Pascoal da Silva, 1721.

CUNHA, D. Luís da. Instruções políticas. Introdução, estudo e edição crítica por Abílio Diniz Silva. Lisboa: Comissão Nacional para as Comemorações dos Descobrimentos Portugueses, 2001.

CUNHA, Luís da. Testamento político ou Carta Escrita pelo Grande D. Luiz da Cunha ao Senhor Rei D. José I antes do seu governo [...]. Lisboa: Impressão Régia, 1820.

CUNHA, Luís da. "Testamento político". In: CONSELHOS aos governantes. Brasília: Edições do Senado Federal, 2010.

MENESES, Sebastião César de. "Suma política". In: CONSELHOS aos governantes. Brasília: Edições do Senado Federal, 2010.

PRADO, Lorenzo Ramirez de. Consejo i consejero de príncipes. Madrid: 1617.

\section{Fontes secundárias}

ARANEDA RIQUELME, José. "Una correspondencia mensual, semanária y a todas horas": correo y espacio in el imperio español durante las reformas borbónicas, siglo XVIII. In: SEMINARIO Simon Collier 2014. Santiago de Chile: Pontificia Universidad Católica de Chile; Instituto de Historia, 2015.

AZEVEDO, J. Lúcio de. "No signo de Methuen”. In: Épocas de Portugal econonómico: esboços de história. 2 ed. Lisboa: Livraria Clássica Editora, 1947.

BATISTA, Felipe de Alvarenga. Os tratados de Methuen de 1703: guerra, portos, panos e vinho. Dissertação de mestrado em Economia Política Internacional. Rio de Janeiro: Universidade Federal do Rio de Janeiro, 2014.

BELOTTO, Manoel Lelo. Correio marítimo hispano-americano: a carreira de Buenos Aires (1767-1779). Assis (SP): Faculdade de Filosofia, Ciências e Letras de Assis, 1971.

BICALHO, Maria Fernanda. A cidade do Rio de Janeiro e o sonho de uma capital americana da visão de D. Luís da Cunha à sede do vice-reinado (1736-1763). História, vol. 30, n.1, São Paulo, 2011. 
BOBBIO, Norberto; MATTEUCCI, Nicola; PASQUINO, Gianfranco. Dicionário de política. 5 ed. Brasília: Editora Universidade de Brasília; São Paulo: Imprensa Oficial do Estado, 2000.

CARVALHO, Joaquim Ramos de. "A rede dos correios na segunda metade do século XVIII". In: SOBRAL NETO, Margarida (coord.). As comunicações na Idade Moderna. Lisboa: Fundação Portuguesa das Comunicações, 2005.

CLUNY, Isabel. D. Luís da Cunha e a ideia de diplomacia em Portugal. Lisboa: Livros Horizonte, 1999.

FURTADO, Júnia Ferreira. “'O oráculo que S. Majestade foi buscar”: d. Luís da Cunha e a geopolítica do novo império luso-brasileiro”. In: FRAGOSO, João; GOUVÊA, Maria de Fátima (org.). Na trama das redes: política e negócios no império português, séculos XVI-XVIII. Rio de Janeiro: Civilização Brasileira, 2010.

FURTADO, Júnia Ferreira. “D. Luís da Cunha - oráculo da geopolítica portuguesa.” In: O mapa que inventou o Brasil. Rio de Janeiro: Versal; São Paulo: Odebrecht, 2013.

GARCIA, Rodolfo. Ensaio sobre a história política e administrativa do Brasil: 1500-1810. Rio de Janeiro: José Olympio; Brasília: INL, 1975.

GAZAGNADOU, Didier. La poste à relais en Eurasie - la diffusion d'une technique d'information et de pouvoir - Chine - Iran - Syrie - Italie. Paris: Kimé, 2013.

HESPANHA, António Manuel. As vésperas do Leviathan: instituições e poder político - Portugal - séc. XVII. Coimbra: Almedina, 1994.

LEONZO, Nanci. “Introdução”. In: CUNHA, D. Luís da. Testamento político ou Carta Escrita pelo Grande D. Luiz da Cunha ao Senhor Rei D. José I antes do seu governo [...] . . São Paulo: Alfa-Ômega, 1976.

MACHADO, Luiz Guilherme G. História geral dos Correios portugueses nos séculos XVI ao XVIII. [s.1.]: 2008. Disponível em: <http://historiapostal.blogspot.com.br>. Acesso em: 24/02/2013.

MAGALHÃES, Joaquim Romero. "O projecto de D. Luís da Cunha para o império português”. In: SILVA, E. Ribeiro da e outros. Estudos em homenagem a Luís António de Oliveira Ramos. Porto: Faculdade de Letras da Universidade do Porto, 2004. Disponível em: 〈http://ler.letras.up.pt/uploads/ficheiros/5002.pdf>. Acesso em: 12/10/2015.

PÉREZ SARRIÓN, Guillermo. "La reorganización del servicio de correos y postas". In: La península comercial: mercado, redes sociales y Estado em España en el siglo XVIII. Madrid: Marcial Pons, 2012. Ebook.

SALVINO, Romulo Valle. Patrimonialização e venalidade no provimento de ofícios no império português: uma abordagem preliminar do caso do correio-mor e seus cargos auxiliares (séculos XVI-XVIII). Postais - Revista do Museu Correios, v. 5, p. 36-75, 2015 b.

SALVINO, Romulo Valle. Uma breve história dos assistentes do correio. Postais - Revista do Museu Correios, V. 4, p. 189-203, 2015a.

SILVA, Abílio Diniz. “Introdução”. In: CUNHA, D. Luís da. Instruções políticas. Introdução, estudo e edição crítica por Abílio Diniz Silva. Lisboa: Comissão Nacional para as Comemorações dos Descobrimentos Portugueses, 2001.

SILVA, Abílio Diniz. , 2003. D. Luís da Cunha e o Tratado de Methuen. Revista da Faculdade de Letras História. Porto, III série, vol. 4, p. 59-84, 2003. Disponível em: <http://ler.letras.up.pt/uploads/ficheiros/2350.pdf>. Acesso em: 15/01/2017.

SOBRAL NETO, Margarida. "Os correios na Idade Moderna”. In: SOBRAL NETO, Margarida (coord.). As comunicações na Idade Moderna. Lisboa: Fundação Portuguesa das Comunicações, 2005.

SODRÉ, Nelson Werneck. "O tratado de Methuen - domínio inglês em Portugal”. In: As razões da independência. Rio de Janeiro: Civilização Brasileira, 1965. 